\title{
LUCC impact on water quality change in Xingyun Lake basin
}

\author{
Xiaolun Zhang ${ }^{1}$, Yanyan Shao ${ }^{2 *}$ \\ ${ }^{1}$ Faculty of Surveying and Mapping, Kunming Metallurgy College, Kunming, Yunnan, 650033, China \\ ${ }^{2}$ The Integrated Institute of Yunnan Bureau of Science, Technology and Industry for National Defense, Kunming, Yunnan, 650118, \\ China
}

\begin{abstract}
Basin ecological environment and water quality are seriously threatened by development around the lake. The thesis intends to assess basin Land Use and land Cover Changes (here after abbreviated as LUCC) impact on water quality change in Xingyun Lake basin. To achieve this purpose, land use information was interpreted from six periods high-resolution images in the past 30 years, which were classified into seven land use types. The water quality data was obtained by investigation and collection. SPSS software was used to celebrate the correlation coefficient between water quality and LUCC. The results revealed that, in the study area construction land, transportation land and farm land were underwent an increase with the region development; grassland and bare land were gradually reduced, forest land had become fragmented. In addition, the water pollution index gradually increased since 2000, the water deteriorated significantly. Furthermore, there was a strong positive correlation between water pollution indicator and farmland, construction land and transportation land, which indicated that the deterioration of water quality may be the result of the combined effects of agriculture non-point source pollution, domestic and industrial pollution; there was a significant negative correlation between water pollution indicator and grassland and bare land, which indicated that permeable underlying mat had significant interception and absorption effects on pollutants.
\end{abstract}

\section{Introduction}

Lake is an important resource for regional economic and social development[1]. The development within the lake basin will cause land use and land cover changes (LUCC)[2-4], and the water quality will affect the ecological environment and people's living quality in the Lake basin. The present research is motivated by the facts that Lake Basin is exploited quickly on the basis of social development projects, leaded to land use tyeps have been changed greatly, and received a serious threat to water quality. Therefore, research and assess the relationship between LUCC and water quality change have the important research significance.

A lot of studies have shown that LUCC had a significant impact on water quality in Lake Basin[5-6], but there were many differences between different regions. Therefore, it is necessary to carry out research on the influence of LUCC on water quality change in Xingyun Lake basin, and it also has regional characteristics.

As one of the important freshwater lakes in central Yunnan Plateau, Xingyun Lake has played a vital role in local economic and tourism development. The lake water and basin ecosystem are under serious threat because of urbanization around the lake. Finding out the relationship between LUCC and water quality change can provide useful information for lake water conservation and land use management in Lake Basin.

This paper is divided into three parts. The first part is an introduction about LUCC, study area status and water quality. Part 2 introduces the research methods of the correlation analysis about LUCC with water quality. In the last part, it analyzes the land use and land cover changes, water quality changes, and discusses the impact of LUCC on water quality.

\section{Materials and Methodologies}

\subsection{A Brief Description of Correlation Analysis}

Correlation analysis can be used to measure the degree of correlation between two variables. Correlation analysis has been applied to study the impact of LUCC on water quality in different regions. Jiang Chang and Liu Hongyan in the 2018 s took correlation analysis method to study the response relationship between Land use change and water quality in Hongfeng Lake basin[6]. Yang Yanan also used this method to study the relationship between Land use pattern and water quality change in Fuxian Lake bain [7].

There are three common correlation coefficients: Spearman, Kendall, and Pearson. In this study, Pearson correlation coefficient was selected to analyse the correlation between water quality and LUCC. Pearson

"Corresponding author's e-mail: 312521384@qq.com 
correlation coefficient reflects two variables linear correlation degree.

\subsection{Acquisition of Key Elements}

\section{(1) Land Use and land Cover Changes}

The LUCC information of Xingyun Lake basin can be obtained by using RS and GIS technologies. First of all, it needs to get high-resolution remote sensing image data in different times. In this study it obtained 6 frames remote sensing images from 1990 to 2016. Secondly, the land use information of Xingyun Lake basin can be extracted by processing remote sensing images. In the end, LUCC can be obtained through land use information in different periods.

(2) Water Quality

In this study, the data of Xingyun Lake water quality in 1990, 1995, 2000, 2005, 2010, and 2016 were obtained by using references and downloading from the official website. Chemical oxygen demand (COD), total phosphorus (TP) and total nitrogen (TN) were selected for water quality analysis. Phosphorus (P) and nitrogen $(\mathrm{N})$ are the main factors leading to water eutrophication, and chemical oxygen demand (COD) can reflect the degree of organic pollution in water.

\subsection{Application of Correlation Analysis to study LUCC impact on Water Quality}

It is reasonable to select the correlation analysis in the research of the response relationship between LUCC and water quality, first of all, there is a clear correlation between LUCC and water quality, and the basin land use change has a significant impact on water quality; the second, the response relationship between LUCC and water quality can be explained clearly and accurately with the correlation coefficient; in the end, the degree of linear correlation between LUCC and water quality can be clearly reflected by Pearson correlation coefficient.

In this study, the software of SPSS19.0 was used for Pearson correlation analysis to explore the response relationship between LUCC and water quality change in the past 26 years.

\section{Analyses and Discussion}

\subsection{Analysis and Discussion on the Basin Land use and land Cover Changes}

Based to the regulations of the Third National Land Investigation and Classification, combined with the actual situation of the basin and research purpose, the land use types in Xingyun Lake basin were determined, which included: farmland, forest land, grassland, construction land, transportation land, water and bare land.

Table1. The land use types of Xingyun Lake basin from 1990 to $2016 \quad\left(\mathrm{~km}^{2}\right)$

\begin{tabular}{ccccccc}
\hline Land use types & 1990 & 1995 & 2000 & 2005 & 2010 & 2016 \\
\hline Farmland & 67.66 & 66.12 & 62.87 & 60.38 & 94.56 & 95.75 \\
Forest land & 50.47 & 49.67 & 64.72 & 66.44 & 70.11 & 50.51 \\
Grassland & 79.72 & 79.58 & 62.61 & 62.46 & 22.59 & 33.21 \\
Construction land & 15.12 & 17.36 & 21.54 & 24.83 & 24.56 & 31.61 \\
Transportation land & 0.62 & 1.13 & 2.53 & 2.79 & 2.86 & 4.31 \\
Water & 36.06 & 36.53 & 35.47 & 34.42 & 37.01 & 37.09 \\
Bare land & 3.19 & 3.45 & 3.10 & 1.52 & 1.15 & 0.36 \\
\hline
\end{tabular}

Land use monitoring results of Xingyun Lake basin from 1990 to 2016 can be seen that (1) all the land use types had the obvious changes; (2) construction land and transportation land showed a gradual upward trend, the areas increased significantly, the construction land area increased from $15.12 \mathrm{~km}^{2}$ to $31.61 \mathrm{~km}^{2}$, and the transportation land area increased from $0.62 \mathrm{~km}^{2}$ to 4.31 $\mathrm{km}^{2}$, this situation was consistent with the development of regional economy and the promotion of urbanization; (3) the area of grassland and bare land had been gradually reduced, the grassland area had been reduced by more than half; (4) the water area fluctuated in a small range, the forestland cover area became fragmentation; (5) the area of farmland was gradually decreasing before 2005, and increased significantly between 2005 and 2010 . All these data implied that business actives around the basin had intensified, water quality had been threatened.

\subsection{Analysis and Discussion Based on Water Quality}

The water quality of Xingyun Lake was Grade III before 1995. With the development of the regional economy, the water quality fell to Grade IV in 2000, and to Grade $\mathrm{V}$ since 2005 . The water quality was in a moderate to severe eutrophication state. Before 2000, the changes of various water pollution indexes were not obvious, but after 2000, the water pollution indexes gradually increased. From 2005 to 2010 , the water pollution index changed significantly and the water quality deteriorated significantly. The rate of deterioration has slowed since 2010.

Xingyun Lake is adjacent to Jiangchuan City, where aquaculture is developed and the surrounding terrain is gentle. Discharge of domestic sewage, unreasonable aquaculture and agricultural non- point source pollution may be the main reasons for the deterioration of water quality. 
Table2. Indices of water pollution from 1990 to 2016

$(\mathrm{mg} / \mathrm{L})$

\begin{tabular}{cccc}
\hline Years & $\begin{array}{c}\text { Chemical Oxygen } \\
\text { Demand(COD) }\end{array}$ & $\begin{array}{c}\text { Total } \\
\text { Phosphorus(TP) }\end{array}$ & Total Nitrogen(TN) \\
\hline 1990 & 3.98 & 0.045 & 0.67 \\
1995 & 4.70 & 0.06 & 0.93 \\
2000 & 5.12 & 0.04 & 0.83 \\
2005 & 6.70 & 0.16 & 1.92 \\
2010 & 34.0 & 0.45 & 2.20 \\
2016 & 38.0 & 0.29 & 2.00 \\
\hline
\end{tabular}

The water pollution indices from 1990 to 2016 shows that chemical oxygen demand was gradually increasing, the other two indexes had increased before 2010, and decreased between 2010 and 2016. All these data means water quality had changed significant in the past 26 years.

\subsection{Analysis and Discussion in Light with Correlation between LUCC and Water Quality}

SPSS software was used to calculate the correlation coefficient between LUCC and water quality.

Table3. Correlation coefficient between LUCC and water pollution indices

\begin{tabular}{cccc}
\hline Land use types & $\begin{array}{c}\text { Chemical Oxygen } \\
\text { Demand }\end{array}$ & Total Phosphorus & Total Nitrogen \\
\hline Farmland & $0.976^{* *}$ & $0.866^{*}$ & 0.669 \\
Forest land & 0.117 & 0.433 & 0.468 \\
Grassland & $-0.935^{* *}$ & $-0.942^{* *}$ & $-0.850^{*}$ \\
Construction land & 0.789 & 0.666 & $0.824^{*}$ \\
Transportation land & 0.761 & 0.636 & 0.780 \\
Water & 0.688 & 0.508 & 0.182 \\
Bare land & $-0.865^{*}$ & $-0.830^{*}$ & $-0.933^{* *}$ \\
\hline
\end{tabular}

Note: ** indicates a significant correlation at the level of 0.01 (bilateral), and * indicates a significant correlation at the level of 0.05 (bilateral)

This may mean that (1) there was a significant positive correlation between farmland and water pollution index, and the correlation coefficients of COD, $\mathrm{TP}$ and $\mathrm{TN}$ reaching $0.976,0.866$ and 0.669 respectively. Farmland was significantly positively correlation with COD, and there was also a strong positive correlation with TP. This may indicate that agricultural non-point source pollution represented by farmland has a strong influence on the water pollution of Xingyun Lake. (2) There was a strong positive correlation between construction land and transportation land and water pollution index, which may indicate that industrial and domestic pollution sources have an important contribution to the introduction of nitrogen and phosphorus in lake water. (3) Both grassland and bare land showed a very strong negative correlation with water pollution index, which may indicate that grassland and bare land had a strong interception effect on surface sewage.

\section{Conclusions}

Through the above analyses and discussion, three conclusions may be drawn that, firstly, there is a significant changes of land use in the Xingyun lake basin in the past 30 years. With the development of the basin construction land, transportation land and farm land increased obviously, but bare land and grassland were gradually reduced. Secondly, the water pollution index gradually increased since 2000. Finally, there was a significant positive correlation between water pollution indicator and farmland, construction land and transportation land, which indicated that the deterioration of water quality may be the result of the combined effects of agriculture non-point source pollution, domestic and industrial pollution; there was a strong negative correlation between water pollution indicator and grassland and bare land, which may indicate that grassland and bare land had a strong interception effect on surface sewage.

The study of the response relationship between LUCC and water quality proves to be inadequate in that the water quality data is annual average, which is inconsistent with land use information in time. Therefore, it is recommended to increase funding for water quality data collection, and detailed research the response relationship between LUCC and water quality in different months or seasons.

\section{Acknowledgments}

This research was supported by Science Foundation of Kunming Metallurgy College (No. 2017xjzk10).

\section{References}

1. Yu Yang, Zhang Min, Qian Shanqin, et al. (2010) Current status and development of water quality of 
lakes in Yunnan- Guizhou Plateau[J]. Journal of Lake Sciences, 22(6): 820-828.

2. Lee S W, Hwang S J, Lee S, et al. (2009) Landscape ecological approach to the relationships of land use patterns in watersheds to water quality characteristics $[\mathrm{J}]$. Landscape and Urban Planning, 92(2): 80-89.

3. Tran et al. (2010) Land-use proximity as a basis for assessing stream water quality in New York State (USA)[J]. Ecological Indicators, 10: 727-733.

4. Hongmei $\mathrm{Bu}$ et al. (2014) Relationships between land use patterns and water quality in Taizi River basin, China[J]. Ecological Indicators, 41: 187-197.

5. Jiang Chang, Liu Hongyan, Chen Zhu, et al. (2018) Response relationship between land-use change and water quality in Hongfeng Lake basin based on GIS[J]. Journal of Agro-Environment Science, 37(6): 1232-1239.

6. Yang Y N, Wang J L, Chen G J, et al. (2016) Relationship between land use pattern and water quality change in Fuxian Lake basin[J]. Remote Sensing for Land and Resources, 28(1):159-165. 